\title{
"A MULHER NO MERCADO": NARRATIVA DE SOFRIMENTO E DENÚNCIA POSTADA NO BLOG DE UMA MULHER COM CÂNCER DE MAMA
}

\author{
Renata Martins Amaral ${ }^{1}$ \\ Maria das Graças Dias Pereira ${ }^{2}$
}

\begin{abstract}
Resumo: Esse artigo investiga o posicionamento narrativo de Vitória, nome fictício de uma mulher em tratamento de câncer de mama que utiliza as redes sociais para compartilhar suas histórias de vida, especialmente, após o diagnóstico da doença. Assim, selecionamos uma narrativa de sofrimento e denúncia postada em seu blog na fase inicial de seu tratamento. Nela é possível identificar temas transversais como estigma, preconceito e resistência através da denúncia. No arcabouço teórico-metodológico, estabelecemos uma interlocução entre estudos sobre performances identitárias na narrativa, discurso como mudança social e posicionamento narrativo. A metodologia da investigação é qualitativa e interpretativa de cunho netnográfico. Desse modo, os objetivos do estudo são: (i) analisar as performances identitárias de Vitória através de uma narrativa postada em seu blog; e (ii) compreender de que forma os discursos da participante apontam para sua transformação em pessoa com mais agência no decorrer de sua luta contra o câncer de mama. A análise indica que: (i) a participante ressignifica sua experiência de dor e lamentação, em uma perspectiva de discurso como ação social com foco na emoção; e (ii) o agenciamento é direcionado aos interlocutores nas redes sociais, enquanto posicionamento político e identitário de enfrentamento do câncer.
\end{abstract}

Palavras-chave: Mulher com câncer de mama. Blog. Performances identitárias. Discurso como ação social. Posicionamento narrativo.

\begin{abstract}
This article investigates the narrative positioning of Vitória, the fictitious name of a woman undergoing breast cancer treatment who uses social networks to share her life stories, especially after the diagnosis of the disease. Thus, we selected a narrative of suffering and denunciation posted on her blog in the initial phase of her treatment. It is possible to identify transversal themes such as stigma, prejudice and resistance through denunciation. The theoretical and methodological framework proposes a dialogue between studies on identity performances in the narrative, discourse as social change and narrative positioning. The research methodology is qualitative and interpretive of a netnographic nature. Thus, the objectives of the study are: (i) to analyze Vitória's identity performances through a narrative posted on her blog; and (ii) to understand how the participant's Discourses point to her transformation into a person with more agency during her fight against breast cancer. The analysis indicates that: (i) the participant reframes her experience of pain and regret, in a
\end{abstract}

\footnotetext{
${ }^{1}$ AMARAL, R.M. é Doutora em Estudos da Linguagem pela Pontifícia Universidade Católica do Rio de Janeiro. A autora tem vínculo institucional com a Secretaria Estadual de Educação do Rio de Janeiro. Seu endereço eletrônico é: martinsamaralrenata@gmail.com.

2 PEREIRA, M.G.D. é Doutora em Letras pela Pontifícia Universidade Católica do Rio de Janeiro. A autora tem vínculo institucional com o Departamento de Estudos da Linguagem da PUC-Rio. Seu endereço eletrônico é: mdgpereira@terra.com.br.
} 
PERcursos Linguísticos • Vitória (ES) •v. 10 •n. 25 • 2020 • ISSN: 2236-2592 • Dossiê:

Discursos de resistência e corpos (re)existentes •

perspective of discourse as social action focusing of emotions; and (ii) the agency is directed to the interlocutors on social networks, as political and identity positioning to face cancer.

Keywords: Woman with breast cancer. Blog. Identity performances. Discourse as social action. Narrative positioning.

\section{Introdução}

No trabalho em tela, investigamos o posicionamento narrativo de Vitória, nome fictício de uma mulher em tratamento de câncer de mama que utiliza as redes sociais para compartilhar suas histórias de vida, especialmente, após o diagnóstico da doença. $\mathrm{Na}$ fase inicial do tratamento, Vitória interage com seus seguidores, principalmente, através de seu blog pessoal. Por ser este um ciberespaço com características semelhantes às do tradicional diário, com nossas experiências do cotidiano, encontramos ali histórias de sofrimento e, ao mesmo tempo, de denúncia, que remetem às suas primeiras experiências de dor e lamentação vivenciadas como mulher com câncer de mama na sociedade brasileira. Assim, através da narrativa intitulada "A mulher no mercado", uma história compartilhada por Vitória em seu blog, será possível observar temas transversais que permeiam a vida cotidiana de mulheres com câncer de mama, como o estigma, o preconceito e a resistência através da denúncia.

Este trabalho faz parte de uma investigação mais abrangente, com enfoque também nas demais fases do tratamento de Vitória, o que nos possibilitou entender que, através de suas postagens online, Vitória constrói-se como sujeito estigmatizado ao descobrir o câncer e, no decorrer do processo, passa a agir como protagonista em redes sociais, por meio da linguagem, na luta contra a doença. Sendo assim, os objetivos deste artigo, que enfoca a fase inicial de seu tratamento, são: (i) analisar as performances identitárias de Vitória através de uma narrativa postada em seu blog; e (ii) compreender de que forma a narrativa apresenta discursos da participante que apontam para sua transformação em pessoa com mais agência no decorrer de sua luta contra o câncer de mama.

Para tanto, o arcabouço teórico eleito conjuga estudos sobre performances identitárias na narrativa (GOFFMAN [1959] 2013, BASTOS, 2005, 2008), discurso como mudança social (FAIRCLOUGH, [1992] 2001; MOITA LOPES, 2002) e posicionamento narrativo (BAMBERG, 1997 e 2002). A metodologia da investigação é qualitativa e interpretativa (DENZIN e LINCOLN, 2006) de cunho netnográfico (KOZINETS, 1997). O excerto em análise consiste em uma narrativa de Vitória que foi compartilhada publicamente em seu blog. 
PERcursos Linguísticos • Vitória (ES) •v. 10 •n. 25 • 2020 • ISSN: 2236-2592 • Dossiê:

Discursos de resistência e corpos (re)existentes •

A seguir, indicamos o posicionamento teórico e metodológico, fazemos a análise da narrativa “A Mulher no Mercado", nossas reflexões e trazemos as considerações finais.

\section{Performances identitárias na narrativa}

Entre as obras desenvolvidas dentro da noção de performance, central para o estudo de narrativas, estamos alinhadas com o trabalho de Erving Goffman ([1959] 2013) A apresentação do eu na vida cotidiana, que tem grande expressividade e nos oferece muitas contribuições para a análise que será apresentada. A relevância da sua abordagem se deve, especialmente, ao fato de estar relacionado à performance de identidade. Goffman traz reflexões sobre o comportamento humano na situação social (GOFFMAN, [1964] 2013a) utilizando a metáfora da representação teatral e partindo de princípios de caráter dramatúrgico para tratar da performance. Nessa metáfora, o mundo é entendido como palco "que apresenta coisas que são simulações" e o indivíduo como ator que "se apresenta sob a máscara de um personagem para personagens projetados por outros atores". Nesse sentido, conforme Goffman, "a plateia constitui um terceiro elemento da correlação, elemento esse que é essencial" ([1959] 2013, p.11; [1964] 2013b).

Conforme sinalizado por Goffman ([1959] 2013), tanto os atores quanto a plateia são muito importantes na composição da cena, já que a situação social é moldada por todos os presentes. Assim, as identidades são construídas a partir das informações que podem ser acessadas em uma dada situação social específica. Informações sobre o indivíduo servem "para definir a situação, tornando os outros capazes de conhecer antecipadamente o que ele esperará deles e o que dele podem esperar" (p. 13). Além disso, o conhecimento prévio de informações sobre o indivíduo pode trazer, de certa forma, confiabilidade a respeito do que o indivíduo "diz de si mesmo ou em provas documentadas que exibe, referentes a quem é e ao que é” (p. 13). Entretanto, muitos fatos estão "além do tempo e do lugar da interação" (p. 14) e, neste caso, só poderão ser verificados e avaliados como "verdadeiros" com base na expressividade do indivíduo, isto é, em sua capacidade de dar impressão. São "verdades" relacionadas a sua expressividade e performance. Segundo Goffman, essa expressividade pode se manifestar de dois modos, a partir da expressão que o indivíduo transmite e da expressão que ele emite.

A expressão que o indivíduo transmite é a comunicação no sentido tradicional ${ }^{3}$, ou seja, que inclui símbolos verbais ou seus substitutos com propósito de veicular informação que todos

\footnotetext{
${ }^{3}$ A posição sobre comunicação aqui é de Goffman, com foco na expressividade e performance. Ver Pereira (2013: p. 73-4), que comenta modelos de comunicação em Schiffrin (1994).
} 
PERcursos Linguísticos • Vitória (ES) •v. 10 •n. 25 • 2020 • ISSN: 2236-2592 • Dossiê:

Discursos de resistência e corpos (re)existentes •

consigam associar a esses símbolos. Já a expressão emitida abrange várias ações, que podem ser consideradas sintomáticas do ator. Tanto as expressões transmitidas quanto as emitidas pelo indivíduo podem, segundo Goffman ([1959] 2013), transmitir "informação falsa intencionalmente" (p. 14), com intenção de que pensem bem a seu respeito. Nesse sentido sua influência sobre os outros é um ponto relevante pois é de seu interesse "atuar de forma a transmitir [aos outros] a impressão que lhe interessa transmitir” (p. 16), o que, por conseguinte, passa a "exercer uma exigência moral sobre os outros, obrigando-os a valorizá-lo e a tratá-lo de acordo com o que as pessoas de seu tipo têm o direito de esperar" (p. 25).

De acordo com Goffman ([1959] 2013), um indivíduo tem inúmeros motivos para controlar a impressão que os outros têm sobre ele em uma interação. $\mathrm{O}$ autor considera como interação "toda interação que ocorre em qualquer ocasião, quando, num conjunto de indivíduos, uns se encontram na presença imediata de outros" (p. 28) e pode ser intercambiado pelo termo "encontro". Nesses encontros, pode-se observar performances - "toda atividade de um determinado participante, em cada ocasião, que sirva para influenciar, de algum modo, qualquer um dos outros participantes" (p. 28) - do participante tomado como referência, assim como dos coparticipantes.

Nesse empreendimento de performances, Goffman ([1959] 2013) afirma que, ao desempenhar um papel, o indivíduo de maneira implícita demanda que seus observadores acreditem em sua impressão, isto é, acreditem em seu personagem. Em outras palavras, o indivíduo solicita que haja crença no papel que ele está representando. Desse modo, o público estaria bem convencido do espetáculo que o ator encena. Se transportarmos essa metáfora de Goffman para as nossas interações sociais cotidianas, um indivíduo que está engajado em um empreendimento de apresentação do self (auto-representação) pode ser considerado um ator social, que ao agir (encenar) no mundo social (palco), constrói sua identidade através de suas performances.

A respeito da representação, Goffman ([1959] 2013) diz ainda que utiliza esse termo para se referir a "toda atividade de um indivíduo que se passa num período caracterizado por sua presença contínua diante de um grupo particular de observadores e que tem sobre estes alguma influência" (p. 34). Aqui, compartilhamos da visão de representação nos termos de Goffman ([1959] 1993) e consideramos que esse conceito está associado à construção de identidades fluídas ou fragmentadas (MOITA LOPES, 2002), mas, sobretudo, com múltiplos papeis. Sendo assim, as performances de identidade são situadas localmente, de acordo com os 
PERcursos Linguísticos • Vitória (ES) •v. 10 •n. 25 • 2020 • ISSN: 2236-2592 • Dossiê:

Discursos de resistência e corpos (re)existentes •

propósitos do ator social. Ao pensarmos nas performances identitárias em narrativas, caberá ao(s) narrador(es) estabelecer(em) os propósitos que ele(s) quer(em) projetar em sua audiência (plateia).

Diante dessa perspectiva teatral, Goffman ([1959] 2013) utiliza princípios da dramaturgia na performance identitária ou apresentação do self (representação). A dramaturgia teatral também está presente em Goffman (1974) como performance (p. 124- 25). A encenação como um espetáculo remete à construção da cena descrita por Goffman (1974 ap. BASTOS, 2005, p. 81; BASTOS, 2008, p. 78) como recontagem de um evento longo por um narrador experiente (Goffman, 1974, p. 504).

Segundo Bastos, parafraseando Goffman (1974), passamos a maior parte do tempo de fala "recontando eventos, isto é, apresentando aos nossos ouvintes versões do que aconteceu, fornecendo evidências da justiça ou injustiça de situações presentes" (BASTOS, 2005, p.81). Segundo a autora, essas recontagens "não são, portanto, meros relatos de eventos, mas sim replayings pessoais e dramáticos de experiências passada" (p.81). A respeito desses replayings, Bastos (2008) retoma:

Em resumo, falar costuma envolver o relato de um evento - passado, corrente, condicional ou futuro, contendo uma figura humana ou não - e esse relato não precisa ser, mas comumente é, apresentado como algo a ser re-experienciado, a ser saboreado, a ser elaborado, ou qualquer outra ação que o apresentador espera que seu pequeno show induza a audiência a experimentar.

(GOFFMAN, 1974, p. 506 ap. BASTOS, 2008, p. $77^{4}$ )

Assim, a narrativa é concebida como um pequeno show do falante, "que envolve e emociona o ouvinte, e não um simples relatório de um evento" (BASTOS, 2008, p. 77), conforme a dramaturgia de Goffman (1974: p. 124- 25). Para a autora, Goffman entende que, ao contar a história, "o narrador se engaja em uma dramatização de sua experiência, organizando-a temporalmente, de sua perspectiva pessoal. É assim caracterizado o aspecto dramático da performance narrativa" (BASTOS, 2008, p. 77).

\section{Discurso como ação e mudança social}

A visão de discurso à qual o trabalho se filia é a de discurso como forma de ação e mudança social (FAIRCLOUGH, [1992] 2001). Nessa abordagem de discurso, não só agimos no cotidiano, mediante discursos que circulam ideológica e socialmente, como também como

\footnotetext{
4 Tradução de Bastos (2008, p. 77).
} 
PERcursos Linguísticos • Vitória (ES) •v. 10 •n. 25 • 2020 • ISSN: 2236-2592 • Dossiê:

Discursos de resistência e corpos (re)existentes •

como são construídos discursivamente no mundo (social) a nossa volta, "nas (redes de) práticas sociais realizadas na (e pela) linguagem” (SANTOS, 2013, p.11).

A esse respeito, Fairclough ([1992] 2001) esclarece que "o discurso é um modo de ação, uma forma na qual as pessoas podem agir sobre o mundo e especialmente umas sobre as outras" (p. 63). Assim, podemos entender que, via discursos, os "atores da mudança social" (CASTELLS, 2013, p. 18) visam mudar as realidades a sua volta. Nessa mesma linha de reflexão, Moita Lopes (2002, p. 93) considera que "as pessoas estão constantemente criando o mundo em volta delas tão bem como elas mesmas e os outros nas práticas sociais onde atuam". Em síntese, “o discurso é uma prática não somente de representar o mundo, mas de significar o mundo, constituindo e construindo o mundo através do significado" (FAIRCLOUGH, 1992, p. $64)$.

É importante destacar que, através dos discursos, os participantes são posicionados em relações de poder. Todavia, eles podem agir em relação uns aos outros, via contradiscursos. Sendo assim, relações de poder não são consideradas fixas, podendo ser contestadas, conforme argumenta Fairclough (1992, p. 45): “os sujeitos sociais são formados por práticas discursivas, contudo também são capazes de remodelarem e reestruturarem estas práticas”. Em relação aos contradiscursos, Moita Lopes (2002) aponta que, em algumas sociedades, partem de grupos não-hegemônicos, como camponeses em luta por terras, pessoas homoeróticas e mulheres, por exemplo.

No presente estudo, Vitória pertence a um grupo marcado como não-hegemônico - o de mulheres com câncer de mama. Seus contradiscursos vão em direção aos discursos preconceituosos e ao descaso da sociedade para/com a comunidade em tratamento da doença.

De acordo com Moita Lopes (2002, p.93), o traço mais marcante do discurso é seu aspecto social, haja vista: (i) sua natureza dialógica (utilizamos a linguagem em relação a alguém que, por sua vez, utiliza a linguagem em relação a nós); (ii) socioconstrucionista (construímos o mundo e as pessoas de acordo com o contexto cultural, histórico e institucional no qual estamos situados); e (iii) a alteridade (através dos discursos nos quais nos engajamos, podemos modificar o outro que, do mesmo modo, também pode nos alterar).

Segundo Moita Lopes (2002, p. 95), "a alteridade implica em moldarmos o que dizemos, assim como nos percebemos à luz do que o outro representa para nós". Sendo assim, à medida em que observamos as identidades dos participantes junto aos discursos, estamos (re)construindo suas identidades nas práticas discursivas em que estão inseridos. Em outras palavras, as práticas discursivas moldam as identidades sociais (FAIRCLOUGH, [1992] 2001). 
PERcursos Linguísticos • Vitória (ES) •v. 10 •n. 25 • 2020 • ISSN: 2236-2592 • Dossiê:

Discursos de resistência e corpos (re)existentes •

Pode-se dizer então que "as identidades são construídas no discurso, sendo, portanto fragmentadas, contraditórias e ambíguas" (MOITA LOPES, 2002, p. 95).

Ao assumirmos o ponto de vista de que as identidades não são qualidades inerentes ao ser humano, e sim concebidas na interação com o(s) outro(s), concordamos com Moore (1988 ap. MOITA LOPES, 2002, p. 95), para quem "não é mais fácil se falar do indivíduo ou do simesmo como uma unidade autônoma e coerente, ao contrário, acabamos por compreender que somos feitos de e vivemos nossas vidas como uma massa de fragmentos contraditórios".

Para Moita Lopes (2002) e Moore (1988), as identidades são fragmentadas e continuamente construídas quando construímos histórias de nossas vidas. Consideramos assim importante voltarmos nossos olhares para a construção identitária nas narrativas que contamos em diversos contextos, sejam presenciais ou virtuais.

No contexto virtual, os textos publicados por Vitória em diferentes ciberespaços possibilitam observar as posições identitárias que Vitória ocupa não somente em diferentes fases de seu tratamento, mas também mediante os Discursos que articula quando atua na e pela ação e mudança social. Discursos como o de Vitória, no excerto que será analisado, extrapolam o nível textual de análise e denunciam estigma e descaso sociais cotidianos, que muitas vezes ecoam vozes da comunidade (oncológica) da qual ela participa (v. DE FINA, 2006).

\section{Posicionamento narrativo}

Vimos, anteriormente, no arcabouço teórico do presente artigo, performances identitárias na narrativa e discurso como mudança social. Nesta seção, detalharemos o conceito de posicionamento narrativo.

Em Bamberg (1997), Positioning Between Structure and Performance, o autor faz considerações sobre o modelo proposto por Labov e Waletzky (1967) para a análise de narrativas, considerando sua abordagem mais estrutural e a temporalidade (orações ordenadas no passado marcando uma sequência de eventos que, de fato, ocorreram). De acordo com Bamberg, apesar do mérito atribuído ao pioneirismo do referido estudo no âmbito das análises de narrativas, esse modelo apresenta limitações por focar sobretudo na textualização, mais do que na função. Para o autor, o modo de olhar para as narrativas deve estar mais voltado para as performances. Nesse sentido, Bamberg (1997) propõe uma abordagem para a avaliação (componente estrutural da narrativa laboviana) que leva em conta contribuições originais de Labov e Waletzky (1967), porém com uma visão mais alinhada à orientação funcionalista. Nesse caso, a temporalidade é vista como um entre outros recursos performáticos que estão a 
PERcursos Linguísticos • Vitória (ES) •v. 10 •n. 25 • 2020 • ISSN: 2236-2592 • Dossiê:

Discursos de resistência e corpos (re)existentes •

serviço de propósitos discursivos e de construção de identidades locais (BAMBERG, 1997, p. 36).

A propósito dos recursos performáticos aos quais Bamberg se refere, são os recursos considerados como pistas de contextualização (GUMPERZ, [1982] 2002). Para Gumperz, as pistas sinalizam, por exemplo, como o(s) narrador(es) quer(em) ser entendido(s). As pistas apontam para significados a serem construídos no processo interativo e apenas validados e reconhecidos em conjunto pelos participantes. As pistas de contextualização podem ser linguísticas (como por exemplo o uso de expressões formulaicas e escolhas lexicais), paralinguísticas (ritmo, pausa e hesitações), prosódicas (entonação, acento e tom de voz) e nãovocais (gestos, movimentos do corpo e do olhar).

A avaliação, nos termos labovianos, é também importante no posicionamento e objetiva informar sobre o clima emocional da situação ou dos protagonistas. É responsável pelas informações sobre a carga dramática e a razão de ser da narrativa, ou seja, o seu ponto. Contudo, segundo Bamberg (1997), em sua proposta de análise de posicionamento "a narrativa é definida consideravelmente de modo mais amplo do que por Labov e Waletzki, para quem a situação e o propósito discursivos são tão centrais quanto a organização semântica da narrativa" (BAMBERG, 1997, p. 341).

Em comparação à concepção de Labov e Waletzki, Bamberg (1997) sugere que sua proposta de análise de posicionamento confere maior centralidade ao engajamento ativo do falante no processo de construção da narrativa. Ademais, "embora as análises de narrativas tradicionalmente tendam a privilegiar as narrativas de experiência pessoal, as narrativas como atos de narração, em geral, servem de igual modo à análise de posicionamento” (p. 342).

Para o autor (opus. cit.), a noção de posicionamento é fundamental para a interpretação da interação através da narrativa. Ao parafrasear Harré e van Langenhove, Bamberg (2002) argumenta que "com o posicionamento, o foco está em como as práticas discursivas constituem os falantes e ouvintes de certas maneiras e, no entanto, ao mesmo tempo, são um recurso pelo qual [eles] podem negociar novas posições" (p. 155). Nesse sentido, as atividades humanas são interpretadas como posicionamentos e as pessoas são concebidas como agentes, que, de forma consciente, se posicionam. À medida que os agentes se autoposicionam, eles também se engajam de forma ativa na construção do próprio mundo e do self (BAMBERG, 2002).

Essa noção de posicionamento narrativo, de certa forma, remete também ao que Gee (1990) denomina como “discursos com 'D’ maiúsculo”. 
Um discurso com uma ' $\mathrm{D}$ ' maiúsculo é composto de formas distintas de falar/ouvir e muitas vezes, também, escrever/ler, juntamente com distintas formas de agir, interagir, valorizar, sentir, vestir, pensar, acreditar, com outras pessoas e com vários objetos, ferramentas e tecnologias, para representar identidades socialmente reconhecíveis engajadas em atividades específicas socialmente reconhecíveis. Essas identidades podem ser coisas como ser - fazer um membro Latino de uma gang de rua de Los Angeles, um policial de Los Angeles, um biólogo de campo, um aluno de primeiro grau em uma sala de aula específica e escola, (...) um certo tipo de médico, advogado, professor, afroamericano, trabalhador em um ambiente de 'controle de qualidade', homem, mulher, namorado, namorada ou frequentador de um bar local, etc. e etc. através de uma lista quase infinita. Os Discursos dizem respeito ao modo como as pessoas 'articulam seus atos juntos' para serem reconhecidas como um determinado tipo de pessoa em um horário e local específicos.

(GEE, 1990, p. 155)

Para Gee (1990), em se tratando de Discursos, o cerne da questão consiste em focar no que as pessoas querem dizer coisas umas às outras, quando sempre há mais do que a linguagem em jogo. A fim de ilustrar o que significa "estar em um Discurso", o autor utiliza a metáfora da dança. Segundo ele, é como poder se engajar em um determinado tipo de 'dança' com palavras, ações, valores, sentimentos, outras pessoas, objetos, ferramentas, tecnologias, lugares e horários. A finalidade é ser reconhecido como um tipo distinto como alguém que faz um determinado tipo de coisa. De acordo com Gee, "ser capaz de entender um Discurso é ser capaz de reconhecer tais 'danças"” (p. 155).

A respeito desses Discursos com 'D' maiúsculo, Bamberg (2002) salienta que as pessoas têm livre-arbítrio para escolherem se orientar por Discursos sociais preexistentes. Dentre uma variedade deles, os indivíduos se engajam interacionalmente na construção discursiva de como fazer sentidos de si próprios e do lugar de pertencimento. Assim, ao se engajarem em algum embate discursivo, as pessoas têm a oportunidade de fazer uso de determinados Discursos para se (re)construirem e, simultaneamente, (re)construirem as identidades de seus interlocutores como determinados tipos de pessoas. Essa visão socioconstrucionista do discurso e das identidades sociais é consoante com a premissa de que cada indivíduo é membro de muitos Discursos, e cada Discurso representa uma de nossas múltiplas identidades (GEE, 1990).

Com base nas reflexões no que tange ao posicionamento narrativo, concordamos com a ideia de que, ao se posicionarem e posicionarem os outros nas interações, as pessoas produzem a si mesmas e aos outros como seres sociais.

No intento de compreendermos as formas como Vitória se auto posiciona e posiciona os outros indivíduos na narrativa, elegemos o modelo de análise de posicionamento 
PERcursos Linguísticos • Vitória (ES) •v. 10 •n. 25 • 2020 • ISSN: 2236-2592 • Dossiê:

Discursos de resistência e corpos (re)existentes •

desenvolvido por Bamberg (1997 e 2002) para nortear a análise do excerto " A Mulher no Mercado". Nesse modelo, o autor propõe três níveis de análise que são orientados por três perguntas:

\begin{tabular}{|c||l|}
\hline NÍVEL & \multicolumn{1}{|c|}{ PERGUNTA NORTEADORA } \\
\hline 1 & $\begin{array}{l}\text { Quem são os personagens e como eles são posicionados em relação uns aos outros } \\
\text { nos eventos reportados? }\end{array}$ \\
\hline 2 & $\begin{array}{l}\text { Como o falante/narrador se posiciona (e é posicionado) na situação interacional diante } \\
\text { de (por) seus interlocutores (audiência)? }\end{array}$ \\
\hline 3 & \begin{tabular}{l} 
Como os narradores se posicionam para si mesmos? \\
\hline
\end{tabular}
\end{tabular}

Quadro 1: Níveis de Posicionamento de Bamberg (1997 e 2002)

A proposta de Bamberg (1997) para desenvolver a noção de posicionamento serve para compreendermos como o trabalho de identidade pode ser realizado especificamente pela narração. De acordo com Bamberg (2002), cada nível de posicionamento tem um foco: no nível 1, o conteúdo da história; no nível 2, o âmbito interacional; no nível 3, o posicionamento do narrador diante de discursos culturais, ou seja, em dimensão mais macro.

De acordo com Bamberg (2002), no nível 1 de posicionamento, investigamos linguisticamente como são construídos os personagens na história, isto é, o modo como os personagens são caracterizados e colocados uns em relação aos outros, buscando responder à pergunta sobre os eventos narrados.

No nível 2 de posicionamento, a fim de elaborar posicionamentos frente a plateias diversas, são feitas diferentes escolhas linguísticas e supralinguísticas para que os interagentes possam chegar a um dado entendimento interativo (BAMBERG, 2002). Os participantes se envolvem na narrativa de forma a criar expectativas sobre a história relatada, fazem avaliações que podem indicar se vale a pena contar a história e negociam a sequência do relato, mostrando que a relevância da história é alcançada na interação. Outra característica do nível 2 de análise diz respeito a como a história se encaixa no contexto da entrevista de pesquisa. $\mathrm{O}$ narrador se posiciona para compartilhar aquilo que sabe, se envolvendo ou resistindo a fornecer uma 
PERcursos Linguísticos • Vitória (ES) •v. 10 •n. 25 • 2020 • ISSN: 2236-2592 • Dossiê:

Discursos de resistência e corpos (re)existentes •

resposta à pergunta formulada, que pode indicar índice de aceitação ou rejeição, por exemplo (BAMBERG e GEORGAKOPOULOU, 2008).

Para Bamberg (2002), embora os níveis 1 e 2 de posicionamento sejam analiticamente distintos, suas fronteiras ainda são tênues. No entanto, entendemos que, no nível 1, a história é construída. Em ambos os níveis, os falantes se posicionam a respeito de quem são, ou seja, em um trabalho contínuo de construção de identidade. Os participantes desenvolvem posicionamento de sujeito que podem se consolidar e dar um sentido de continuidade do self, e suas questões morais são indexadas em conjunto pelos participantes.

O nível 3 de posicionamento está associado às ações desencadeadas face aos Discursos com 'D' maiúsculo (fora da situação), os mesmos aos quais Gee (1990) se refere. No terceiro nível, há uma preocupação em compreender como a linguagem é usada para defender os pontos de vista do narrador, suas crenças, que vão além daquela conversa e o posicionam em um contexto macro. Desse modo, o nível 3 visa ao posicionamento do sujeito face aos Discursos que circulam na sociedade e ideologias (BAMBERG, 2002).

Segundo De Fina (2013), esse nível de análise explora como o narrador/falante posiciona um senso de self/ identidade no que diz respeito aos discursos dominantes e como o sujeito faz esse posicionamento relevante para a interação no "aqui" e "agora", e assim se constrói como um tipo particular de pessoa. A autora sugere ainda que a análise deva ter exclusivamente uma direção, partir do nível micro para acessar o nível macro a fim de se compreender os macroprocessos de construção de identidade. Assim, os discursos localizados nas narrativas se relacionam a estruturas mais amplas como Discursos, construtos culturais e narrativas hegemônicas. Em outras palavras, De Fina (2013) defende que o nível 3 de posicionamento envolva a conexão do que é dito em nível local com processos e Discursos pertencentes a uma escala diferente.

Do ponto de vista de De Fina (2013), a natureza e relevância de ideologias e Discursos para o posicionamento local podem também ser estabelecidos além do nível individual e local ao se olhar para os padrões da comunidade, isto é, para as tendências gerais na forma como as questões são vistas e tratadas pelas comunidades às quais os indivíduos pertencem. Desse modo, a autora argumenta que os padrões apontam para a existência de representações coletivas, que por sua vez, podem estar relacionadas a processos sociais mais amplos, como lutas econômicas e culturais. Como salienta De Fina (2013), o nível 3 de posicionamento envolve posições individuais face aos Discursos, mas tais posições podem se tornar comuns entre os diferentes membros de uma comunidade e apontar para processos de posicionamento coletivo. 
PERcursos Linguísticos • Vitória (ES) •v. 10 •n. 25 • 2020 • ISSN: 2236-2592 • Dossiê:

Discursos de resistência e corpos (re)existentes •

Ao retomar os três níveis de análise de posicionamento propostos, Bamberg (1997) afirma que o arranjo sequencial dos mesmos obedece a uma organização: iniciar a análise em âmbito textual/narrativo, em seguida passar para o nível interacional (como os falantes se colocam), e, finalmente, estabelecer como os falantes chegam a fazer sentidos de si próprios (BAMBERG, 2002). Além de concordar com essa organização, De Fina (2013) entende que a interpretação do posicionamento está baseada em: (i) na análise minuciosa do discurso em nível local; (ii) nos dados etnográficos; e (iii) na compreensão dos processos macrossociais subjacentes às relações de poder.

Com base na estrutura analítica dos estudos de Bamberg (1997 e 2002), Bamberg e Georgakopoulou (2008) e De Fina (2013), que seguem os três níveis de análise, a saber, partem suas análises do nível 1, passam pelo nível 2 e chegam ao nível 3 -, no presente estudo o excerto selecionado também será analisado por níveis - primeiro o nível 1, depois o nível 2 e, finalmente, o nível 3 - um de cada vez. Com esta metodologia aliada ao entendimento funcional das categorias de Labov, faremos a análise da narrativa "A Mulher no Mercado" após a seção seguinte, a metodologia da pesquisa.

\section{Metodologia da pesquisa}

Ao pensarmos no desenvolvimento da pesquisa em que se insere o presente artigo (AMARAL, 2018), optamos pela perspectiva qualitativa que, como afirmam Denzin e Lincoln (2006), é interdisciplinar, multifacetada e tem um enfoque multipragmático. Essa perspectiva tem sido privilegiada nas áreas humanas e sociais para descrever, compreender ou explicar os fenômenos relacionados à vida em sociedade. Nesse sentido, "seus praticantes são suscetíveis ao valor da abordagem de múltiplos métodos, tendo um compromisso com a perspectiva naturalista e a compreensão interpretativista da experiência humana" (p. 21). Entre os pressupostos da pesquisa qualitativa, inserem-se os de natureza interpretativista, que representa uma forma de compreender as práticas sociais em seus "cenários naturais, tentando entender, ou interpretar, os fenômenos sociais em termos de significados que as pessoas a eles conferem" (DENZIN e LINCOLN, 2006, p. 17).

No entanto, com o advento das tecnologias de informação e comunicação, doravante denominadas TICs, passamos a experimentar inovações nas formas de agrupamento social, comportamentos, culturas e nas manifestações discursivas. Nesse sentido, Kozinets (2014, p. 09) afirma que "nossos mundos sociais estão se tornando digitais". Essa premissa implica uma

\footnotetext{
${ }^{5}$ A tese é intitulada: "De lagarta a borboleta: protagonismo de mulheres com câncer de mama em redes sociais".
} 
PERcursos Linguísticos • Vitória (ES) •v. 10 •n. 25 • 2020 • ISSN: 2236-2592 • Dossiê:

Discursos de resistência e corpos (re)existentes •

necessidade de se repensar os modos de compreender a sociedade. Para o autor, é preciso "seguir as atividades sociais e interações das pessoas na Internet e por meio de outros meios de comunicação mediados pela tecnologia" (p.09).

Sendo assim, novos métodos de investigação passaram a ser pensados, mediante a inquietude a respeito da utilização de métodos tradicionais para a realização de estudos contemporâneas no contexto digital. Dessa demanda surgiu na academia a metodologia de pesquisa conhecida como netnografia. Esse termo foi utilizado pela primeira vez em 1998 pelo norte-americano Robert Kozinets e pode ser aproximado da tradicional etnografia; contudo a netnografia é feita em ambiente digital. Para o autor, a netnografia se apresenta como uma metodologia apropriada a investigações no ciberespaço. Kozinets (2014) explica que a netnografia utiliza comunicações mediadas por computador como fonte de dados para chegar à compreensão e à representação etnográfica de um fenômeno cultural na Internet. Sua abordagem é importante para estudar fóruns, grupos de notícias, blogs e redes sociais em geral, com as alterações necessárias a netnografia como uma metodologia em potencial no contexto da pesquisa, junto à pesquisa qualitativa.

A seguir, fazermos a análise do excerto selecionado para o presente artigo.

\section{Análise da narrativa "A Mulher no Mercado"}

$\mathrm{Na}$ fase inicial do tratamento, mais precisamente no dia 14 de janeiro de 2012, Vitória contou em seu blog "Divã de Vitória Peixoto" (nome fictício de seu blog) um episódio que aconteceu em sua vida no dia anterior, durante sua ida ao mercado acompanhada de seu filho Bruno, na época um menino de 9 anos de idade.

Vitória postou uma narrativa que tem como título "A mulher no mercado". A partir das escolhas lexicais que compõem o título da narrativa, Vitória - narradora e personagem da história - orienta sua audiência para uma personagem de destaque do que potencialmente será contado. Até aqui, o que a narradora informa à audiência é uma posição de destaque para essa mulher que é localmente situada em um mercado, mas não se sabe ainda se se trata de uma protagonista, antagonista ou coadjuvante.

\section{A Mulher no Mercado}

01 O dia de hoje foi ótimo, produtivo e motivador. Eu estava realmente muito bem até

02 resolver ir ao supermercado. Tudo normal, afinal, o que pode haver de tão

03 ameaçador numa simples ida à um supermercado? 
04 Iniciei minhas compras e estava distraída c/ meu filho, escolhendo quais os sabores

$05 \mathrm{p} /$ pipocas de microondas, quando uma moça, que eu nunca vi na vida, me cutucou,

06 pediu licença e me perguntou: "vc se curou?"

07 Eu, pega de surpresa e sem entender a intenção da pergunta, respondi

08 automaticamente que SIM.

09 E ela completou: "Tomara que sim. Tive uma amiga que teve câncer de mama e que

10 tb pensou que tinha se curado, mas quatro anos depois apareceu uma metástase e

11 ela morreu". Virou as costas e saiu, como se nada tivesse acontecido. Travei.

12 Gente!!!!! Perdi o chão. O meu filho, tadinho, arregalou os olhos assustado. Só me

13 fez uma pergunta óbvia: "mãe, vc conhece essa mulher?"

14 Conclusão: Não consegui terminar minhas compras e entrei em desespero... me vi de

15 novo dentro do mundo paralelo, perdida. Caí em prantos, no meio do supermercado.

16 Fiz um esforço enorme $\mathrm{p} /$ manter o controle por conta do Bruno, que ficou sem

17 entender nada.

18 Voltamos rapidinho $\mathrm{p} /$ casa e $\mathrm{p} /$ completar, nossa noite de sábado terminou $\mathrm{c} / \mathrm{um}$

19 black-out por conta de um vendaval que atingiu toda a baixada santista. Com a

20 cabeça bombando de dor, tomei um banho gelado à luz de velas. Me debulhei em

21 lágrimas numa dor emocional aguda, um transbordamento... adormeci.

Nível 1 de Posicionamento: Quem são os personagens e como eles são posicionados em relação uns aos outros nos eventos reportados?

Na narrativa em análise, há quatro personagens: duas principais e dois coadjuvantes. As personagens principais são Vitória, que também assume o papel de "mãe" (linha 13), e a mulher no mercado, que é tratada pela narradora como "uma moça" (linha 05) e, por um dos personagens coadjuvantes no diálogo reconstruído pela narradora, como "essa mulher" (linha 13). Os personagens secundários ou coadjuvantes são Bruno (o filho de Vitória) e uma amiga da mulher do mercado, que não é apresentada por seu nome, apenas por uma referência mais abstrata (BAMBERG, 2002).

Ao focar na avaliação que a narradora e também personagem principal faz dos personagens ao longo de toda a narrativa (LABOV e WALETZKY, 1967), percebo que, já na ação complicadora, Vitória atribui recursos avaliativos a si própria como uma pessoa "distraída" (linha 04) e na conclusão como uma pessoa "em desespero" (linha 14) e "perdida" (linha 15). Além disso, ela avalia Bruno demonstrando pena do menino "tadinho" e "assustado" (linha 12). Sendo assim, ambos recebem atributos desfavoráveis para agentividade. No entanto, ao se referir à moça que é responsável por tornar um evento ordinário (a ida ao mercado) em um evento com status de contável, Vitória utiliza a oração avaliativa "que nunca vi na vida" (linha 05), marcando distanciamento entre ambas. 
PERcursos Linguísticos • Vitória (ES) •v. 10 •n. 25 • 2020 • ISSN: 2236-2592 • Dossiê:

Discursos de resistência e corpos (re)existentes •

Iniciei minhas compras e estava distraída c/ meu filho, escolhendo quais os sabores $\mathrm{p} /$ pipocas de microondas, quando uma moça, que eu nunca vi na vida, me cutucou, pediu licença e me perguntou: "vc se curou?"

Eu, pega de surpresa e sem entender a intenção da pergunta, respondi automaticamente que SIM.

E ela completou: "Tomara que sim. Tive uma amiga que teve câncer de mama e que tb pensou que tinha se curado, mas quatro anos depois apareceu uma metástase e ela morreu". Virou as costas e saiu, como se nada tivesse acontecido. Travei.

Ao avaliar as ações dos personagens, Vitória se constrói como uma personagem central que se revela à mercê de forças externas. Em outras palavras, como uma pessoa que sofre com as ações de outros sujeitos ou circunstâncias.

$\mathrm{Na}$ orientação da narrativa, a narradora avalia o dia como "ótimo, produtivo e motivador" (linha 01). Segundo ela, tudo estava "muito bem”, "normal” (linhas 01 - 02). Contudo, as ações indesejáveis da mulher no mercado contribuíram para a desestabilização do self de Vitória, haja vista que inesperadamente a desconhecida "cutucou", "pediu licença" e perguntou à narradora “vc se curou?” (linhas 05 - 06).

A partir desse ponto na narrativa, a sequência de orações do diálogo reconstruído narrado por Vitória - "uma amiga...tb pensou que tinha se curado", "quatro anos depois apareceu uma metástase e ela morreu" e "virou as costas e saiu" (linhas 09 - 11) - apontam maior grau de agentividade discursiva da desconhecida e, em contrapartida, nuances rumo a um assujeitamento de Vitória “Travei” e "Perdi o chão" (linhas 11 - 12). Na resolução da narrativa, Vitória ratifica sua posição de mártir através da negação da ação "Não consegui terminar minhas compras" e da sequência de eventos "entrei em desespero", "me vi de novo num mundo paralelo", "caí em prantos" e "me debulhei em lágrimas" (linha 14 - 20).

No âmbito da narração, através dos dispositivos avaliativos dos personagens e das ações das personagens centrais, Vitória se posiciona como protagonista, sofredora e como sujeito com menos agência, e na contramão, ela posiciona a mulher no mercado como antagonista, cruel e como sujeito com mais intenção. Bruno e a amiga da mulher no mercado são posicionados pela narradora como coadjuvantes e, assim como ela, alvos das ações da antagonista, só que indiretamente.

Diante desta caracterização dos personagens da narrativa, destacamos que, na fase inicial do tratamento, Vitória se projeta como a protagonista da história, mas a agentividade da antagonista que é representativo do que Fairclough (1992) esclarece acerca do discurso. De acordo com o autor "o discurso é um modo de ação, uma forma na qual as pessoas podem agir 
PERcursos Linguísticos • Vitória (ES) •v. 10 •n. 25 • 2020 • ISSN: 2236-2592 • Dossiê:

Discursos de resistência e corpos (re)existentes •

sobre o mundo e especialmente umas sobre as outras" (MOITA LOPES, 2002, p. 93). Logo, o poder do discurso da mulher no mercado interfere diretamente sobre o self de Vitória.

Nível 2 de posicionamento: Como o falante/narrador se posiciona (e é posicionado) na situação interacional diante de (por) seus interlocutores (audiência)?

Para iniciar a análise do segundo nível de posicionamento, vale retomar uma questão estrutural do ponto de vista analítico: trata-se de uma narrativa canônica. Diferentemente das narrativas orais contadas em situação de entrevista ou que são co-narradas, essa é uma narrativa escrita em um blog. Neste ciberespaço, que funciona como uma espécie de diário, as postagens são mais longas (as narrativas são mais completas, do ponto de vista das narrativas tipicamente labovianas), sem interrupções e há pouca ou quase nenhuma interação, como no caso do segmento em análise.

A audiência de Vitória é uma audiência projetada, provavelmente composta por pessoas que a conhecem e gostam de acompanhar suas histórias postadas no "Divã de Vitória Peixoto" (GOFFMAN, [1959] 2013; [1964] 2013b). Vitória escreve para uma audiência projetada porque suas escolhas das formas linguísticas e das características de desempenho servem para elaborar posições diante de sua audiência (BAMBERG, 2002). Analisamos assim como a narradora se posiciona para a audiência, mas, como não há registro escrito e nem oral no âmbito da interação no blog, não foi possível investigar como a narradora é posicionada por seus interlocutores.

No excerto em questão, Vitória se posiciona para sua audiência projetada, os seguidores de seu blog, como vítima no cenário interacional apresentado pela narrativa. Uma estratégia discursiva que a narradora utiliza para marcar esse posicionamento é trazer para seus interlocutores a ação complicadora através de diálogo reconstruído com a sua própria voz e com a voz da antagonista (a mulher no mercado) em discurso direto. Ao recriar a cena - "quando uma moça, que eu nunca vi na vida, me cutucou, pediu licença e me perguntou: 'vc se curou?'/ $\mathrm{Eu}$, pega de surpresa e sem entender a intenção da pergunta, respondi automaticamente que SIM./ E ela completou: 'Tomara que sim. Tive uma amiga que teve câncer de mama e que tb pensou que tinha se curado, mas quatro anos depois apareceu uma metástase e ela morreu" (linhas $05-11)$-, Vitória confere veracidade aos eventos narrados. Através desta estratégia linguística, a narradora e protagonista da história oferece aos seus interlocutores o acesso direto às suas experiências e identidades (BAMBERG, 2002). 
PERcursos Linguísticos • Vitória (ES) •v. 10 •n. 25 • 2020 • ISSN: 2236-2592 • Dossiê:

Discursos de resistência e corpos (re)existentes •

Como afirma Bastos (2005), as narrativas são importantes para compreendermos a nós próprios e as relações que estabelecemos com os outros. Nesse empreendimento, nos construímos discursivamente como seres socialmente inseridos e nossas construções identitárias não são necessariamente autênticas (BAMBERG, 2002), mas refletem a maneira como queremos ser compreendidos.

Conforme Moita Lopes (2002), acerca do caráter fluido e fragmentado das identidades, percebemos que Vitória se constrói inicialmente como uma pessoa motivada e "muito bem" (linha 01) para realizar suas atividades rotineiras como ir ao mercado em companhia de seu filho. No entanto, a ação da antagonista de indagá-la sobre seu tratamento - provavelmente ao julgar a aparência física de Vitória (um lenço na cabeça ou o corpo inchado em decorrência da medicação, por exemplo) típica da fase inicial do tratamento de câncer - motivou a desestabilização do self da protagonista da história. Em decorrência desta instabilidade, Vitória nega a verdade sobre estar curada "respondi automaticamente que SIM" (linhas 07 e 08), talvez para receber um feedback positivo da mulher no mercado e encerrar os questionamentos da estranha. A partir deste momento, sua performance identitária passa a ser a de vítima daquela situação interacional e pode ser percebida através de uma sequência de ações "travei”, "perdi o chão", "não consegui terminar minhas compras", "entrei em desespero" e "caí em prantos" (linhas $12-15)$.

Assim, apesar de ser a protagonista da história narrada, Vitória se constrói na maior parte da narrativa como um sujeito assujeitado, não-agente (MARTINS FERREIRA, 2017), incapaz de reagir contra os discursos da mulher no mercado.

Nível 3 de posicionamento: Como os narradores se posicionam para si mesmos?

A análise do nível 3 de posicionamento nos leva a compreender como Vitória quer ser entendida por sua audiência a partir de uma construção identitária localmente situada que pode ser relacionada a Discursos mais amplos, construções culturais e narrativas hegemônicas (DE FINA, 2013). Com isso, é possível associar as posições do narrador, suas crenças que perpassam a situação interacional, com posicionamentos em um macro contexto.

No caso de Vitória, percebemos que um possível assujeitamento e um grau de sofrimento e dor diante dos discursos da mulher no mercado refletem posições comumente assumidas por pessoas em tratamento de câncer de mama, face aos discursos hegemônicos que circulam na sociedade brasileira sobre a doença. Esses discursos frequentemente associam o câncer de mama à sentença de morte ou outro estigma depreciativo. Com a difusão e o caráter 
PERcursos Linguísticos • Vitória (ES) •v. 10 •n. 25 • 2020 • ISSN: 2236-2592 • Dossiê:

Discursos de resistência e corpos (re)existentes •

libertário das redes sociais (CASTELLS, 2013), tem sido cada vez mais comum a emergência de marcas de estigma relacionadas ao câncer de mama nas narrativas de mulheres com a doença que interagem no ciberespaço (AMARAL, 2017). De acordo com a autora, essas mulheres publicitam marcas de estigma nas redes sociais digitais contemporâneas e, com isso, ressignificam suas experiências de lamentação, tornando-as instrumentos de denúncia e descontentamento político (AMARAL e PEREIRA, 2015).

Com base nas reflexões acima pudemos inferir que, no âmbito interacional, Vitória assume a posição de "vítima" da sociedade, de sujeito assujeitado e, aparentemente, com pouca agência no que diz respeito às ações de oposição por parte do indivíduo (AHEARN, 2001). No entanto, se considerarmos a concepção de agência como uma forma de ação social e pensarmos em seu posicionamento em um macro contexto, Vitória se revela um sujeito com agência, que surge da dor como um modo de ação (ASAD, 2003; SILVA, 2010). O fato de Vitória tratar questões que envolvem estigmas sociais, por exemplo, em ringues públicos digitais corrobora a necessidade de discutirmos essa problemática também em espaços urbanos, em um hibridismo entre redes sociais (CASTELLS, 2013). Destarte, o conteúdo difundido entre seus seguidores a partir de sua narrativa sobre a mulher no mercado, ainda de modo incipiente - por refletir uma inquietação da fase inicial de seu tratamento e compartilhamento de experiências sobre o câncer de mama em seu blog -, já aponta a posição de Vitória como ator social (CASTELLS, 2013; MARTINS FERREIRA, 2017).

\section{Considerações}

A análise indica que: (i) a participante ressignifica sua experiência de dor e lamentação, em uma perspectiva de discurso como ação social via discursos de emoção; e (ii) o agenciamento é direcionado aos interlocutores nas redes sociais, enquanto posicionamento político e identitário de enfrentamento do câncer.

Nossa proposta de análise da narrativa com base na interlocução entre performances identitárias na narrativa, discurso como mudança social e posicionamento narrativo, por meio de uma metodologia de investigação qualitativa e interpretativa de cunho netnográfico, nos pareceu bastante profícua. A partir de nossos objetivos, pudemos compreender que Vitória, em suas performances identitárias inicialmente construídas no âmbito do sujeito com menos agência, para a ressignificar sua experiência de dor e lamentação, em uma perspectiva de discurso como ação social via discursos de emoção. Dessa forma, a participante direciona seu 
PERcursos Linguísticos • Vitória (ES) •v. 10 •n. 25 • 2020 • ISSN: 2236-2592 • Dossiê:

Discursos de resistência e corpos (re)existentes •

agenciamento aos interlocutores nas redes sociais, enquanto posicionamento político e identitário de enfrentamento do câncer.

Ao situarmos a narrativa de Vitória para o macro contexto social viabilizado pela Internet, percebemos o compartilhamento de sua história de vida como uma possibilidade de entendermos que a descoberta de uma doença invasiva como o câncer de mama não representa o fim da vida. Pelo contrário, o estudo apresenta a alternativa da transformação, da mudança de posicionamento do self no mundo social. Experiências de dor e sofrimento podem ser redimensionadas em práticas sociais de enfrentamento da doença através das redes sociais.

Quando Vitória opta por dividir sua experiência com seus interactantes virtuais, além de denunciar Discursos estigmatizadores em função de sua aparência física sob os efeitos da doença, ela também tende a se tornar inspiradora de outros sujeitos. Sua narrativa compartilhada no ciberespaço convida seus interlocutores a repensarem os modos de lidar com as mudanças trazidas pela doença.

\section{Referências}

AHEARN, L. M. Language and agency. Annual Review of Anthropology, California, v. 30, p. 109-137, 2001. Disponível em: https://doi.org/10.1146/annurev.anthro.30.1.109. Acesso em 09 de novembro de 2017.

AMARAL, R. M. e PEREIRA, M. G. D., Discussing Breast Cancer in Cyber Spaces: a Pragmatic Study. 14 ${ }^{\text {th }}$ IPrA Conference, Belgium. 2015.

AMARAL, R. M. "Pobres coitados estão com os dias contados": marcas de estigma nos discursos de mulheres com câncer de mama postados no contexto digital. XI Jornada de Estudos do Discurso - Estigma na Vida Social. 2017. Disponível em https://jedpucrio.wixsite.com/jedpucrio Acesso em 12 de janeiro de 2018.

. "De lagarta a borboleta": Protagonismo de mulheres com câncer de mama em redes sociais. Tese (Doutorado em Estudos da Linguagem). Rio de Janeiro. Pontifícia Universidade Católica do Rio de Janeiro, 2018.

ASAD, T. Formations of the secular: Christianity, Islam, Modernity. Stanford: Stanford University Press, 2003.

BAMBERG, M. G. W. Construindo a masculinidade na adolescência: posicionamentos e o processo de construção da identidade aos 15 anos. In: Moita Lopes, L. P. \& Bastos, L. C. (orgs.) Identidades: recortes multi e interdisciplinares. Campinas: Mercado de Letras, cap. 8, p. 149 $185,2002$.

. Positioning between structure and performance. Journal of Narrative and Life History. Volume 7 (1 - 4), p. 335 - 342, 1997. 
PERcursos Linguísticos • Vitória (ES) •v. 10 •n. 25 • 2020 • ISSN: 2236-2592 • Dossiê:

Discursos de resistência e corpos (re)existentes •

BAMBERG, M. \& GEORGAKOPOULOU, A. Small stories as a new perspective in narrative and identity analysis. Text \& Talk, [S.1.], v. 28, n. 3, p. 377-396, 2008.

BASTOS, L. C. Contando estórias em contextos espontâneos e institucionais - uma introdução ao estudo da narrativa. In: Calidoscópio. Vol. 3, n. 2, maio/agosto, 2005.

BASTOS, L. C. Diante do sofrimento do outro - narrativas de profissionais de saúde em reuniões de trabalho. In: Calidoscópio. Vol. 6, 2008. p. 76-85.

CASTELLS, M. Redes de indignação e esperança: movimentos sociais na era da internet/Manuel Castells; tradução Carlos Alberto Medeiros. - 1.ed. - Rio de Janeiro: Zahar, 2013.

DE FINA, A. Positioning level 3: Connecting local identity displays to macro social processes. Narrative Inquiry, 23 (1), John Benjamins Publishing Company, p. 40-61, 2013.

DE FINA, A. Group Identity, narrative and self-representations. In: DE FINA, A., SCHIFFRIN, D., BAMBERG, M. (Orgs.) Discourse and identity. Cambridge: Cambridge University Press, 2006. p. 351-375. Disponível em http://www.administradores.com.br/artigos/tecnologia/oprotagonismo-das-manifestacoes-esta-no-social-e-nao-no-facebook/71395/ Acesso em 02 de dezembro de 2017.

DEPPERMAN, A. Editorial: Positioning in narrative interaction. Narrative Inquiry, 23 (1), John Benjamins Publishing Company, p. 1-15, 2013.

DENZIN, N. K.\& LINCOLN, Y. S. Planejamento da pesquisa qualitativa: teorias e abordagens. Porto Alegre: Artmed, 2006.

FAIRCLOUGH, N. Discourse and Social Change. Cambridge: Polity Press, 1992.

FAIRCLOUGH, N. Discurso e mudança social. Brasília: Editora Universidade de Brasília, 2001.

GEE, J.P. Social Linguistics and literacies: Ideology in discourses. Bristol:The Falmer Press, p. $155-158,1990$.

GOFFMAN, E. A representação do eu na vida cotidiana. Tradução de Maria Célia Santos Raposo.19. ed. Petrópolis: Editora Vozes, [1959] 2013.

. A apresentação do eu na vida de todos os dias. Tradução de Miguel Serras Pereira. Lisboa, Relógio d'Água. ([1959] 1993).

a. A situação negligenciada. In: RIBEIRO, Branca Telles; GARCEZ, Pedro M. (orgs.) Sociolinguística Interacional. $2^{a}$ ed. São Paulo: Edições Loyola. [1964] 2013. pp. 1320.

b. Footing. In: RIBEIRO, Branca Telles; GARCEZ, Pedro M. (orgs.) Sociolinguística Interacional. $2^{a}$ ed. São Paulo: Edições Loyola. [1964] 2013. pp. 107-148. 
PERcursos Linguísticos • Vitória (ES) •v. 10 •n. 25 • 2020 • ISSN: 2236-2592 • Dossiê:

Discursos de resistência e corpos (re)existentes •

Frame analysis. An Essay on the Organization of Experience. Boston: Northeastern University Press, 1974.

GUMPERZ, J. J. Convenções de contextualização. In: RIBEIRO, Branca Telles; GARCEZ, Pedro M. (Org.). Sociolingüística interacional. 2. ed. São Paulo: Loyola, p. 149-182, 2002.

. Discourse strategies. Cambridge, Cambridge University, 1982.

KOZINETS, R. On Netnography: Inicial Reflections on Consumer Research Investigations of Cyberculture, 1997.

. Netnografia: Realizando pesquisa etnográfica online. Porto Alegre: Penso, 203 p. 2014.

LABOV, W. \& WALETZKY, J. Narrative Analysis: oral versions of personal experience. In: HELM, J. (Org.). Essays on the verbal and visual arts. Seattle: University of Washington Press, 1967.

MARTINS FERREIRA, D. M. Do semelhante ao mesmo, do diferente ao semelhante: sujeito, ator, agente e protagonismo na linguagem. In: RBLA, Belo Horizonte, aop0617, 2017.

MOITA LOPES, L. P. Identidades fragmentadas: a construção discursiva de raça, gênero e sexualidade em sala de aula. Coleção Letramento, Educação e Sociedade. Campinas, SP: Mercado das Letras, 2002.

MOORE, S. "Getting a bit of the other: pimps of postmodernism". In: CHAPMAN, R. e RUTHERFORD, J. (eds.). Male order. Londres, Lawrence e Wishart, 1988.

PEREIRA, Maria das Graças Dias. Discordâncias na interação entre atendentes e clientes em uma Central de Atendimento de Seguro Saúde: o cumprimento do mandato institucional com estratégias de convencimento. ReVEL. v. 11, n. 21, 2013.

SANTOS, G. P. O Jornal Aurora da Rua e o protagonismo na situação de rua: um estudo crítico. Brasília, 203 p. Dissertação de Mestrado - Departamento de Linguística, Português e Letras Clássicas, Universidade de Brasília, 2013.

SCHIFFRIN, D. Approaches to discourse. Massachusetts: Blackwell Publishers, 1994.

SILVA, D. N. e. Pragmática da violência: o Nordeste na mídia do Brasil. São Paulo, 181 p. Tese de Doutorado - Curso de Linguística do Instituto de Estudos da Linguagem, Universidade Estadual de Campinas, 2010. 